Journal of Applied Pharmaceutical Science Vol. 5 (11), pp. 095-100, November, 2015

Available online at http://www.japsonline.com

DOI: $10.7324 / \mathrm{JAPS} .2015 .501116$

ISSN 2231-3354 (cc) BY-NC-SA

\title{
Effect of Trigonella Foenum-Graecum seed powder on anthropometrical and nutritional parameter
}

\author{
Victoria KONOPELNYUK ${ }^{1 *}$, Larysa KOT ${ }^{1}$, Sándor MAKAI² ${ }^{2}$ Ludmila OSTAPCHENKO $^{1}$ \\ ${ }^{1}$ Educational and Scientific Centre "Institute of Biology" of Taras Shevchenko National University of Kyiv, 64/13, Volodymyrska Street, City of Kyiv, \\ Ukraine. ${ }^{2}$ Institute of Crop Sciences, Faculty of Agricultural and Food Sciences, Department of Medicinal and Aromatic Plants, University of the West \\ Hungary, Mosonmagyaróvár, H-9200, Hungary.
}

\section{ARTICLE INFO \\ Article history: \\ Received on: 30/06/2015 \\ Revised on: 17/07/2015 \\ Accepted on: 09/09/2015 \\ Available online: 27/11/2015}

Key words:

Obesity, fenugreek, body

weight, food intake.

\begin{abstract}
The purpose of this study was to assess effect of powder from Trigonella foenum-graecum seed anthropometrical and nutritional parameters of obese rats. This study was carried out on rats with initial weighing of 155-185 g. Rats of the control group have been fed with a standard food and water for 14 weeks. Rats of the experimental groups have been fed by a high-caloric diet for 14 weeks and fed by a standard chow which containing: fenugreek (2\%.) During the research it was determined the main indicators of obesity such as body weight, food intake, body mass index, specific rate of body mass gain, energy intake, feed efficiency et al. Studies have shown that the addition of $2 \%$ powder from Trigonella foenum-graecum seed in food promoted weight loss and other anthropometrical and nutritional parameters.
\end{abstract}

\section{INTRODUCTION}

Overweight and obesity, as well as their related diseases, are considered a problem of developed countries and developing countries (WHO, 2013). Caloric-dense diets, high fat, increased urbanization and psychosocial stress, sedentary lifestyles are the most common contributing factors (Chooi Y Lee, 2013). Its prevalence is increasing in adults and children, and has been described by the WHO as a global epidemic with an estimated 500 million obese adults and 1.5 billion overweight or obese individuals worldwide (WHO, 2000; Finucane, 2011). Obesity is associated with an overall increase in mortality and a decrease in lifespan of up to 20 years (Fontaine et al., 2003). Over the years, many medications have been used to manage obesity. However, many drugs have been with drawn form

\footnotetext{
* Corresponding Author

Victoria KONOPELNYUK, Educational and Scientific Centre

"Institute of Biology" of Taras Shevchenko National University of Kyiv, 64/13, Volodymyrska Street, City of Kyiv, Ukraine.

Email:: konopelnyuk@rambler.ru
}

market due to unacceptable side effects (Joo and Lee, 2014). In this regard, there is a need of new potential antiobesity drug to combat this syndrome. Further studies such as clinical outcome for longer period or for a specific age group are needed, it is obvious that the progression of pharmacotherapy for obesity treatment gives us chance to manage weight problem more effectively. Trigonella foenum-graecum L. (fenugreek, Fg) is an important annual medicinal plant of the Leguminosae family and its leaves and seeds have been used in various illnesses and as a health tonic for a very long time (Yadav and Baquer, 2014). In traditional Chinese medicine, fenugreek seeds are used as a general tonic to improve metabolism and health as well as a treatment for weakness and edema of legs (Wang et al., 2013). Fenugreek is known to have hypoglycemic, hypocholesterolaemic, antioxidant potency, digestive stimulant action, and hepatoprotective effects (Bashri et al., 2013).

The present study was therefore undertaken with an objective to examine the effects of Powder From Trigonella foenum-Graecum Seed (henceforth -fenugreek, Fg) on anthropometrical and nutritional parameters. 


\section{MATERIALS AND METHODS}

Research was conducted in compliance with the standards of the Convention on Bioethics of the Council of Europe's 'Europe Convention for the Protection of Vertebrate Animals' used for experimental and other scientific purposes' (1997), the general ethical principles of animal experiments, approved by the First National Congress on Bioethics Ukraine (September 2001) and other international agreements and national legislation in this field. Animals were kept in a vivarium that was accredited in accordance with the 'standard rules on ordering, equipment and maintenance of experimental biological clinics (vivarium)'. Instruments to be used for research are subject to metrological control.

\section{Animals and housing conditions:}

Studies conducted on 40 Wistar rats and divided to four groups of 10 animals each. The animals of each experimental group were individually housed in polypropylene cages in an environmentally controlled clean air room, with a temperature of $22 \pm 3 \mathrm{C}$, a $12 \mathrm{~h}$ light/12 h dark cycle and a relative humidity of $60 \pm 5 \%$.

\section{Animals and diet}

Rats of group 1 (Control, C) were given water ad libitum and were fed by a standard chow during 14 weeks of the experimental period. Food consumption was measured daily at the same time (09:00 to 10:00 h) and body weights were determined once a week.

The (HCD) group was fed by a high-caloric diet, which contained: standard chow (60\%), lard (10\%), eggs $(10 \%)$, sucrose $(9 \%)$, peanut $(5 \%)$, dry milk (5\%), vegetable oil (1\%) and water ad libitum (Shen and Tang, 2010). Food consumption was measured daily at the same time (09:00 to 10:00 h). The body weights were determined once a week.

Rats of group 3 (CFg) were fed by a standard chow which containing: fenugreek (2\%). Food consumption was measured daily at the same time (09:00 to 10:00 h). The body weights were determined once a week.

The (HCDFg) group was fed by, a high-caloric diet, which contained: standard chow (60\%), lard (10\%), eggs (10\%), sucrose $(9 \%)$, peanut $(5 \%)$, dry milk $(5 \%)$, vegetable oil $(1 \%)$ and fenugreek $(2 \%)$ during 14 weeks of the experimental period. Food consumption was measured daily at the same time (09:00 to 10:00 h) and body weights were determined once a week.

Seeds of Trigonella foenum graecum L. varieties Ovari 4 were provided by Professor of the University of West Hungary Sándor Makai (Institute of Crop Sciences, Department of Medicinal and Aromatic Plants).

\section{Anthropometrical and nutritional determinations}

Body length (nose-to-anus or nose-anus length) of all animals was measured. The body weight and body length were used to determine the following anthropometrical parameters:
Body mass index $(\mathrm{BMI})=$ body weight $(\mathrm{g}) /$ length ${ }^{2}\left(\mathrm{~cm}^{2}\right)($ Novelli et al., 2007)

Specific rate of body mass gain $(\mathrm{g} / \mathrm{kg})=\mathrm{dM} / \mathrm{M} \mathrm{dt}$, where $\mathrm{dM}$ represents the gain of body weight during $d t=t_{2}-t_{1}$ and $M$ is the rat body weight at $\mathrm{t}_{1}$ (Novelli et al., 2007)

Based on food and caloric intake (Diniz et al. 2005), the following nutritional parameters were calculated:

Energy intake $(\mathrm{kJ} /$ day $)=$ mean food consumption $\mathrm{x}$ dietary metabolizable energy (Novelli et al., 2007)

Feed efficiency $(\mathrm{FE} ; \mathrm{g}$ gained/kcal $)=($ mean body weight gain $(\mathrm{g})$ 100) / total energy intake (kcal) (Cope et al., 2007)

\section{RESULTS}

Body weight of all experimental groups of animals during 14 weeks is shown in Figure 1. The initial weight of the animals in the control group was $167,333 \pm 17,332 \mathrm{~g}$, after 14 weeks of an experiment a gradual increase of this indicator was shown. The final body weight of the animals in the control group was $325,266 \pm 4,911 \mathrm{~g}$, which was $157,9 \mathrm{~g}$ more than the initial. It was found that after 14 weeks of consumption high-calorie diet body weight of rats was significantly higher in comparison with initial weight (initial weight $179.9 \pm 18.076 \mathrm{~g}$ and final weight $416,3 \pm 9,511 \mathrm{~g}, \mathrm{p}<0.05)$. Throughout the period of the development of obesity it was shown a gradual increase in body mass of rats and the body weight of HCD group rats had been increased by $236,4 \mathrm{~g}$ compared with initial weight.

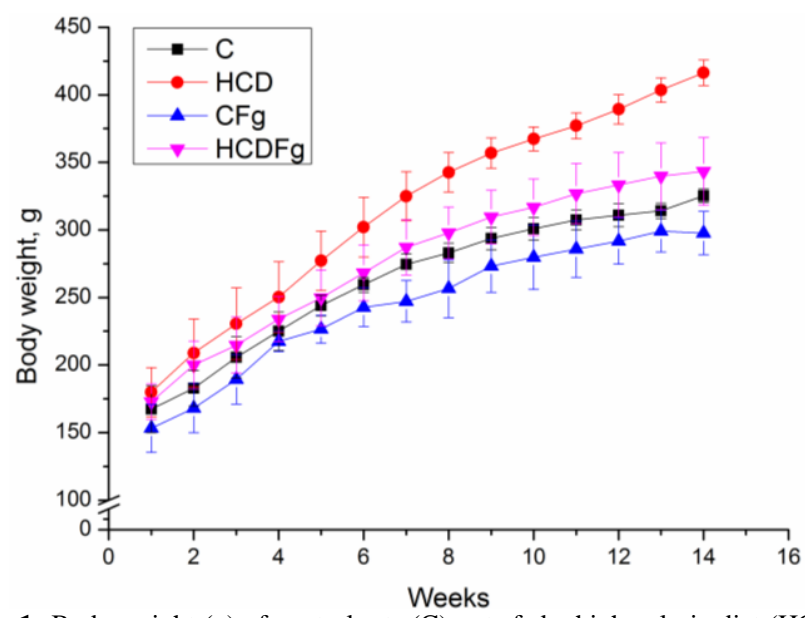

Fig. 1: Body weight (g) of control rats (C), rats fed a high-calorie diet (HCD), rats fed a high- calorie diet with fenugreek $(\mathrm{HCDFg})$ and control rats with fenugreek (CFg) during 14 weeks.

Animals fed with diet containing $2 \%$ of fenugreek seed powder showed reduced body weight. In the $\mathrm{CFg}$ group of rats an increase of body weight by $144,4 \mathrm{~g}$ was recorded compared with the initial weight, which was $153,2 \pm 17,718 \mathrm{~g}$. However, the final weight of this group of animals was reduced by $27,6 \mathrm{~g}$ compared to the control group. The initial weight of rats that were on a highcalorie diet with containing $2 \%$ of fenugreek seed extract was $172.866 \pm 13.319 \mathrm{~g}$. The increase in body weight after 14 weeks of experiment was $170,5 \mathrm{~g}$ compared with the initial weight of the 
animals in the group. However, comparing the change in body weight in the HCD group and HCDFg shows that the final body weight of rats $\mathrm{HCDFg}$ group $73 \mathrm{~g}$ less than final body animals HCD group.

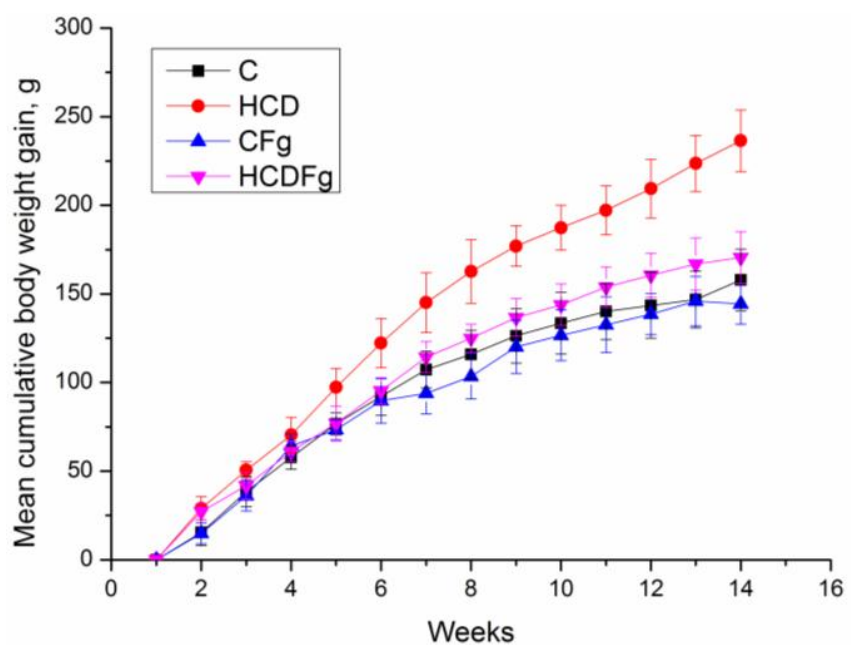

Fig. 2:Cumulative body weight gain (g) of control rats $(\mathrm{C})$, rats fed a highcalorie diet (HCD), rats fed a high- calorie diet with fenugreek (HCDFg) and control rats with fenugreek $(\mathrm{CFg})$ during 14 weeks.

Figure 3 shows specific rate of body mass gain of all experimental groups $(\mathrm{C}, \mathrm{HCD}, \mathrm{CFg}, \mathrm{HCDFg})$ of animals during 14 weeks. The specific rate of body mass gain in $\mathrm{HCD}$ and $\mathrm{HCDFg}$ groups was significantly decreased with increasing time of experiment. In the $\mathrm{C}$ and $\mathrm{CFg}$ groups of animals observed a lower specific rate of weight gain during the experiment.

The cumulative food intake increased in rats during the period of the experiment. Mean cumulative food intake of control rats $(\mathrm{C})$, rats fed a high-calorie diet $(\mathrm{HCD})$, rats fed a highcarbohydrate diet with fenugreek $(\mathrm{HCDFg})$ and control rats with fenugreek $(\mathrm{CFg})$ during 14 weeks is shown in Figure 4 and 5. In $\mathrm{CFg}$ group of animals observed increase of cumulative food intake compared to all other groups.

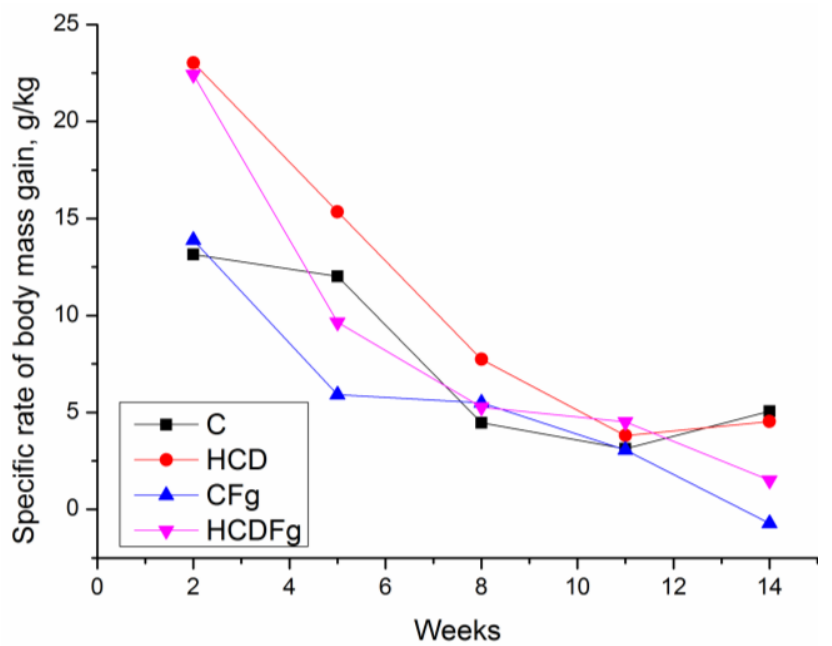

Fig. 3: Specific rate of body mass gain $(\mathrm{g} / \mathrm{kg})$ of control rats $(\mathrm{C})$, rats fed a high-calorie diet (HCD), rats fed a high- calorie diet with fenugreek (HCDFg) and control rats with fenugreek $(\mathrm{CFg})$ during 14 weeks.
Figure 3 shows the increased food intake in a $\mathrm{CFg}$ group of animals during 14 weeks. Other groups were not observed significant differences between the food intake.

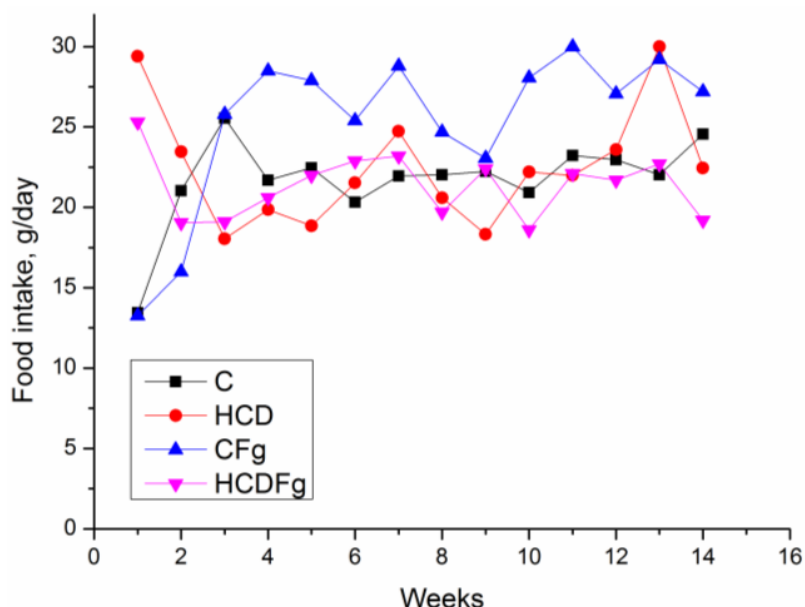

Fig. 4: Food intake (g/day) of control rats (C), rats fed a high-calorie diet (HCD), rats fed a high- calorie diet with fenugreek ( $\mathrm{HCDFg}$ ) and control rats with fenugreek $(\mathrm{CFg})$ during 14 weeks

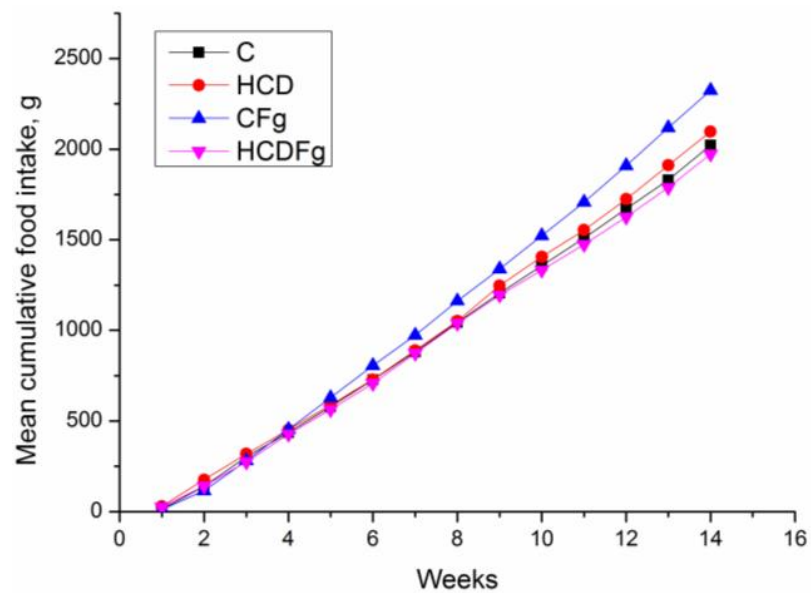

Fig. 5: Cumulative food intake (g) of control rats (C), rats fed a high-calorie diet (HCD), rats fed a high- calorie diet with fenugreek $(\mathrm{HCDFg})$ and control rats with fenugreek $(\mathrm{CFg})$ during 14 weeks

Table 1 shows the general characteristics of animals. HCD rats had significantly higher final body weight, body weight gain and specific rate of body mass gain than did $\mathrm{C}$ rats. The food consumption was not significantly changed in all groups of rats compared to control group. HCD animals had the highest energy intake, since the energy was from food intake in these animals. Nevertheless CFg and HCDFg animals had the higher energy intake compared to control group. The FE was higher in HCD, $\mathrm{CFg}$ and in $\mathrm{HCDFg}$ rats than in $\mathrm{C}$ (Table 1). The body length was comparable in all groups. Body mass index was higher in HCD group of animals than in the control group. Body mass index was at control values in a group of animals CFg and HCDFg (Figure 6). Figure 7 shows that HCD rats had significantly higher cumulative feeding efficiency, than $\mathrm{C}$ rats. In the group of animals CFg decreased efficiency of feeding compared with controls. The same trend persisted in the group HCDFg compared to the values of the group HCD. 


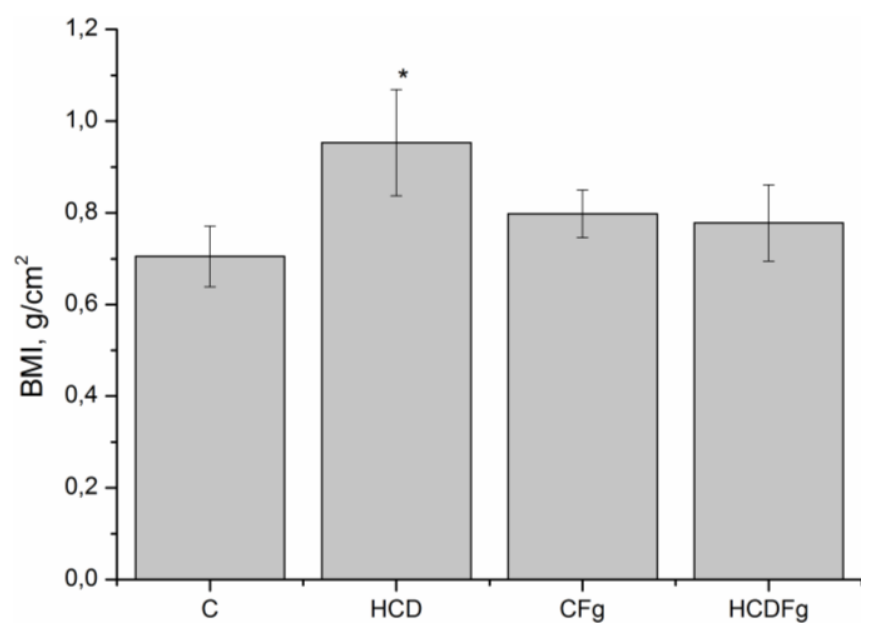

Fig. 6: Body mass index (BMI) in control rats (C), rats fed a high-calorie diet (HCD), rats fed a high-calorie diet with fenugreek (HCDFg) and control rats with fenugreek $(\mathrm{CFg})$ during 14 weeks. $*$ - $\mathrm{p}<0.05$ compared to control group, \# - $\mathrm{p}<0.05$ compared to HCD-group

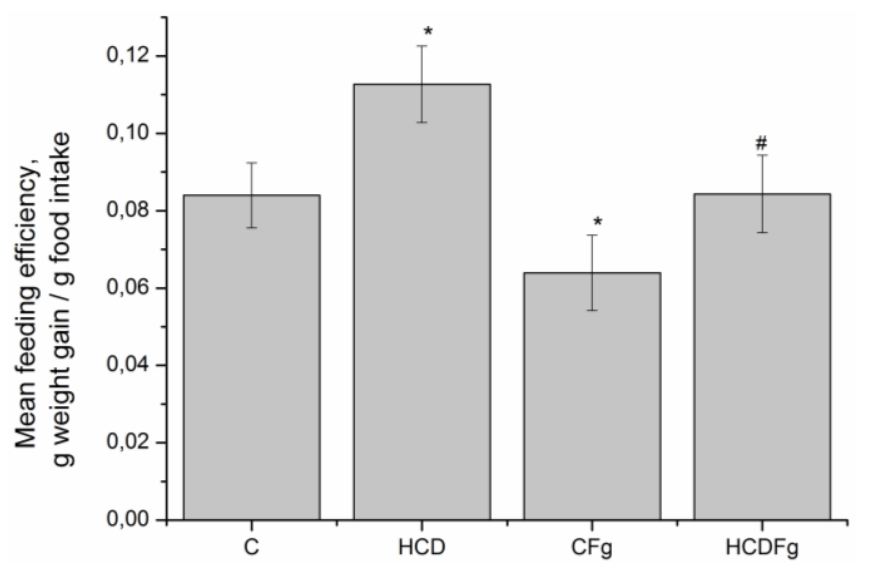

Fig. 7: Cumulative feeding efficiency in control rats $(\mathrm{C})$, rats fed a high-calorie diet (HCD), rats fed a high-calorie diet with fenugreek (HCDFg) and control rats with fenugreek $(\mathrm{CFg})$ during 14 weeks. $*-\mathrm{p}<0.05$ compared to control group, \# - $\mathrm{p}<0.05$ compared to HCD-group

Table 1: Body weight gain, specific rate of body mass gain, food consumption, energy intake and feed efficiency (FE), body length, in control rats (C), rats fed a high-calorie diet (HCD), rats fed a high- calorie diet with fenugreek (HCDFg) and control rats with fenugreek (CFg) during 14 weeks.

\begin{tabular}{|c|c|c|c|c|}
\hline \multirow{2}{*}{ Parameters } & \multicolumn{4}{|c|}{ Groups } \\
\hline & $\mathbf{C}$ & HCD & CFg & HCDFg \\
\hline Body weight gain (g/day) & $1,611 \pm 0,177$ & $2,412 \pm 0,174 *$ & $1,474 \pm 0,115$ & $1,739 \pm 0,146 \#$ \\
\hline Specific rate of body mass gain $(\mathrm{g} / \mathrm{kg})$ & $9,631 \pm 1,132$ & $13,409 \pm 1,542 *$ & $9,622 \pm 1,643$ & $10,063 \pm 1,098$ \\
\hline Food consumption (g/day) & $22,321 \pm 1,434$ & $22,532 \pm 1,211$ & $24,991 \pm 1,112^{*}$ & $21,203 \pm 1,221$ \\
\hline Energy intake (kJ/day) & $308,107 \pm 15,451$ & $384,107 \pm 16,324 *$ & $345,273 \pm 18,542 *$ & $362,605 \pm 14,653^{*}$ \\
\hline Feed efficiency $(\%)$ & $2,366 \pm 0,114$ & $2,764 \pm 0,201 *$ & $1,883 \pm 0,141 *$ & $2,118 \pm 0,232 \#$ \\
\hline Body length $(\mathrm{cm})$ & $21,466 \pm 1,043$ & $20,933 \pm 1,015$ & $19,372 \pm 1,183$ & $21,032 \pm 1,209$ \\
\hline
\end{tabular}

$*$ - $\mathrm{p}<0.05$ compared to control group, \# - $\mathrm{p}<0.05$ compared to HCD-group.

\section{Statistics}

Statistical analysis performed by using 'Statistica 7.0' software. All data in this study were expressed as means \pm standard deviation $(\mathrm{M} \pm \mathrm{SD})$. Data distribution was analyzed using the Shapiro-Wilk normality test. Continuous variables with parametric distribution were then analyzed using Analysis of Variance (ANOVA) and if the results were significant, a Fisher's LSD Post Hoc test was performed. For data with non-parametric distribution Kruskall-Wallis test was used. Estimation of gender specific changes performed using Student's $t$ test for unpaired values. The difference between groups was defined to be statistically significant when a p-value was less than 0.05 .

\section{DISCUSSION}

The most important reasons associated with obesity includes changes in dietary pattern, lack of physical activity, sedentary lifestyle, lack of sleep, endocrine disorders, irregular metabolism, medications that make patients put on weight, psychological and infectious disorders. Diet and behavioral modification programs for weight loss and the prevention of weight regain aim to reduce energy intake and to increase energy expenditure. Today, there are several treatments for obesity. One is a change in the way nutrition and exercise. Another method of weight loss can be called as expensive surgery. Another method is the use of drugs, called pharmacological agents which reduce or control weight. Drugs regulating weight by altering appetite, metabolism, absorption of calories. But now allowed (FDA) to use only one anti-obesity medication - orlistat, which is inhibiting pancreatic lipase reduces intestinal fat absorption (Colon-Gonzalez et al., 2013).

Today more and more to treat various chronic diseases commonly used herbal supplements because they have less toxic effects than chemically synthesized drugs and are cost effective. Recent preliminary reports suggested that herbs might be effective in reducing appetite and promoting significant weight loss are encouraging.

Thus medicinal plants and the chemicals derived from plants have gained the interest of public and scientists for their role in maintaining health and preventing disease. The medicinal plant with potential efficacy to prevent obesity is briefly discussed. As one promising candidate, in this study, we investigated antiobesity effects of Fg in HCD-induced obese rat.

Consumption of high caloric intake in form of HCD induces the development of obesity in rats. Obesity is characterized by body weight gain due to an increase in numbers and sizes of adipocytes (Karpovets et al., 2014; Konopelnyuk et al., 2015). Thus, it is important to reduce body weight and body fat to prevent obesity, and the increase in body fat mass. In our study, a significant reduction in body weight with Fg treatment indicates that Fg suppresses the HCD-mediated increase in body weight. Fg reduced body weight gain and specific rate of body mass gain 
significantly compared with HCD induced obese rat. These results indicate that Fg effectively inhibited body weight gain.

Despite a significant difference in body weight between the HCD and control groups, there was no significant difference in food intake. However, with additions extract Fg in standard chow for control group animals they consumed more food. Thus there was a slight reduction in body weight in the group of animals $\mathrm{CFg}$ compared with the control group.

According to the literature there are 3 main bioactive compounds of fenugreek: diosgenin, 4-hydroxyisoleucine (4-OHIle), and the soluble dietary fiber fraction of fenugreek seeds (Fuller and Stephens, 2015). The fiber component of fenugreek seeds is largely made up of galactomannans, which are polysaccharides consisting of a mannose backbone linked to galactose side groups (Roberts, 2011). Chemical compositions of aqueous extract of Trigonella foenum-graecum seeds: amino acid, phenolic, flavonoid, and galactomannan (Omezzine et al., 2014). In our opinion there are two possible mechanisms of fenugreek decreasing the total body weight: - fenugreek flushes out the carbohydrates from the body before they enter the blood stream resulting in weight loss; - fenugreek seeds contain a high proportion $(40 \%)$ of soluble fiber. This fiber forms a gelatinous structure (similar to gaurgum) which may have effects on slowing the digestion and absorption of food from the intestine and create a sense of fullness in the abdomen, thus suppresses appetite and promotes weight loss.

Consumption of fenugreek in addition to a standard chow and high-caloric diet enhanced satiety and fullness and reduced hunger and reported prospective food consumption compared to standard chow and high-caloric diet. Reducing energy intake was seen in $\mathrm{CFg}$ and HCDFg compared to HCD. The presence of the viscous fiber from fenugreek may have played a role in promoting satiety by slowing the rates of gastric emptying. Fenugreek galactomannan has been shown to slow gastric emptying in animal models (Hannan et al., 2007).

However, according to research Punna Ramulu, was shown to increase excretion of feces in rats which food was added fenugreek (Ramulu et al., 2011). This could be due to high content of fenugreek seeds. Higher excretion of feces means higher excretion of fecal bile acids and neutral sterols, as shown earlier by Bhat et al. (1995) by feeding fenugreek and also by Sharma (1984) using different gums (Kumar et al., 2012). In summary, it could be conclusively said, that the earlier observation of hypolipidemic effect observed using fenugreek is mainly due to fenugreek seeds (galactomannan) present in them. The possible mechanism of action of GM could be due to increased activity of HMG-CoAR and concomitant excretion of bile acids and neutral sterols in feces. The effects on appetite suppression and food intake suggest that fenugreek may have a role in the control of food intake in obese individuals. Because weight loss achieved by rats following diets in this study occurred without emphasizing caloric restriction, some individuals may find these types of dietary patterns easier to follow over the long term, according to the researchers. With more and more people rejecting chemical drugs due to the fear of side effects, natural-based products are fast gaining popularity, thus justifying extensive research in this field.

\section{REFERENCES}

Bashri Gausiya, Vijay Pratap Singh, Sheo Mohan Prasad A Review on Nutritional and Antioxidant Values, and Medicinal Properties of Trigonella foenum-graecum L. Biochem Pharmacol, 2013; 2:3.

Bhat BG, Sambaiah R, Chandrashehara N. The effect of feeding fenugreek and ginger on bile composition in the albino rat. Nutr. Rep. Int., $1985 ; 32: 1145-1151$.

Diniz YS, Faine LA, Galhardi CM, et al. Monosodium glutamate in standard and high-fiber diets: metabolic syndrome and oxidative stress in rats. Nutrition, 2005; 21:749-55.

Chooi Y Lee. The Effect of High-Fat Diet-Induced Pathophysiological Changes in the Gut on Obesity: What Should be the Ideal Treatment? Clinical and Translational Gastroenterology, 2013; 4, e39.

Colon-Gonzalez F, Kim GW, Lin JE, Valentino MA, Waldman SA. "Obesity pharmacotherapy: what is next?" Molecular Aspects of Medicine, 2013; 34(1):71-83.

Cope MB, Jumbo-Lucioni P, Walton RG, Kesterson RA, Allison DB, Nagy TR. No effect of dietary fat on short-term weight gain in mice treated with atypical antipsychotic drugs. International Journal of Obesity, 2007; 31:1014-1022.

Finucane MM, Stevens GA, Cowan MJ, Danaei G, Lin JK, Paciorek CJ, Singh GM, Gutierrez HR, Lu Y, Bahalim AN, et al. National, regional, and global trends in body-mass index since 1980: systematic analysis of health examination surveys and epidemiological studies with 960 country-years and $9 \cdot 1$ million participants. Lancet, 2011; 377:557567.

Fontaine KR, Redden DT, Wang C, Westfall AO, Allison DB. Years of life lost due to obesity. JAMA, 2003; 289:187-193.

Fuller Scott and Stephens Jacqueline M. Diosgenin, 4Hydroxyisoleucine, and Fiber from Fenugreek: Mechanisms of Actions and Potential Effects on Metabolic Syndrome. American Society for Nutrition. Adv. Nutr., 2015; 6:189-197

Jong Kil Joo and Kyu Sup Lee. Pharmacotherapy for Obesity. J Menopausal Med, 2014; 20(3):90-96.

Hannan JMA, Ali L, Rokeya B, Khaleque J, Akhter M, Flatt PR, Abdel-Wahab YHA. Soluble dietary fibre fraction of Trigonella foenum-graecum (fenugreek) seed improves glucose homeostasis in animal models of type 1 and type 2 diabetes by delaying carbohydrate digestion and absorption, and enhancing insulin action. Br J Nutr, 2007; 97:514-521.

Karpovets TP, Konopelnyuk VV, Savchuk OM, Ostapchenko LI. Food behavior of rats under development of obesity. Research Journal of Pharmaceutical, Biological and Chemical Sciences, 2014; 5(5):253-259.

Konopelnyuk V, Yurchenko A, Karpovets T, Ostapchenko L. The development of obesity and prediabetes under conditions of longterm consumption of fructose solution in rats. Journal of Applied Pharmaceutical Science, 2015; 5(1):001-005.

Kumar P, Kale RK, Baquer NZ. Antihyperglycemic and protective effects of Trigonella foenum graecum seed powder on biochemical alterations in alloxan diabetic rats. Eur Rev Med Pharmacol Sci., 2012; 3:18-27.

Lim A Young, Su Yeon Kim, In Seok Lee, Ryowon Choue. Impaired Bone Formation with a High-Protein Diet in Rats with Adriamycin-Induced Nephrotic Syndrome, Kidney Blood Press Res. 2012; $35: 438-444$

Novelli ELB et al. Anthropometrical parameters and markers of obesity in rats Laboratory Animals Ltd. Laboratory Animals 2007; 41:111-119.

Omezzine F. et al. Chemical composition and antifungal activity of Trigonella foenum-graecum L. varied with plant ploidy level and developmental stage. Arabian Journal of Chemistry, 2014; http://dx.doi.org/10.1016/j.arabjc.2014.03.013

Punna Ramulu, Nappan Veettil Giridharan, Paruchuri Udayasekhararao. Hypolipidemic effect of soluble dietary fiber 
(galactomannan) isolated from fenugreek seeds in WNIN (GR-Ob) obese rats. Journal of Medicinal Plants Research, 2011; 5(19):4804-4813.

Roberts KT. The potential of fenugreek (Trigonella foenumgraecum) as a functional food and nutraceutical and its effects on glycemia and lipidemia. J Med Food, 2011;14(12):1485-9.

Sharma RD. Hypocholesterolemic activity of fenugreek an experimental study in rat. Nutr. Rep. Int., 1984; 30:221-231.

Umesh C. S. Yadav, Najma Z. Baquer. Pharmacological effects of Trigonella foenum-graecum L. in health and disease. Pharmaceutical Biology, 2014; 52(2 ):243-254.

Wang Zhijun, Jeffrey Wang, Patrick Chan. Treating Type 2 Diabetes Mellitus with Traditional Chinese and Indian Medicinal Herbs Evid Based Complement Alternat Med, 2013; 2013:343-594.

World Health Organization. Obesity and overweight. http://www.who.int/mediacentre/factsheets/fs311/en/\# (accessed on 4 November 2013).

World Health Organization. Obesity: preventing and managing the global epidemic. Report of a WHO consultation. World Health Organ Tech Rep Ser, 2000;894:i-xii, 1-253.

Xiu-Hua Shen, Qing-Ya Tang, Juan Huang. Vitamin E regulates adipocytokine expression in a rat model of dietary-induced obesity, Exp Biol Med, 2010; 235(1):47-51.

\section{How to cite this article:}

Victoria KONOPELNYUK, Larysa KOT, Sándor MAKAI, Ludmila OSTAPCHENKO. Effect of Powder From Trigonella Foenum-Graecum Seed on Anthropometrical And Nutritional Paramet. J App Pharm Sci, 2015; 5 (11): 095-100. 